\title{
Tensile Strength of Banana Fiber Reinforced Epoxy Composites Materials
}

\author{
Agustinus Purna Irawan ${ }^{1, a}$ and I Wayan Sukania ${ }^{1, b}$ \\ ${ }^{1}$ Mechanical Engineering Department, Tarumanagara University, Jakarta, Indonesia \\ ${ }^{2}$ Industrial Engineering Department, Tarumanagara University, Jakarta, Indonesia \\ agustinus@untar.ac.id, biwayansukania@yahoo.com
}

Keywords: Natural fiber composites, banana fiber, epoxy, tensile strength

\begin{abstract}
Indonesia is one of countries with the potential for abundant natural resources, especially natural fibers. The potential of Indonesian natural fibers abundant is not fully put to good use to increase social welfare. One of the natural fibers that have the potential to be developed is the banana fiber. Banana fiber has potential in abundance and can be developed as a biocomposite material that is strong, inexpensive, environmentally friendly, and can be recycled. This study aims to produce a tensile strength of Banana Fiber Reinforced Epoxy Composite Materials (BFRECM). Testing of the tensile strength refers to the ASTM D 3039 / D3039M. Based on the research results, obtained the tensile strength of BFRECM $(62.3 \pm 0.67) \mathrm{MPa}$ and modulus of elasticity $(8.72 \pm 1.12)$ $\mathrm{GPa}$. Tensile strength obtained will be referred for further study of natural fiber composites.
\end{abstract}

\section{Introduction}

The research of Banana Fiber Reinforced Epoxy Composite Materials (BFRECM) used as an alternative material for making prosthesis is a new field of research and still open to be developed. This study is based on the potential of banana fiber is abundant in Indonesia, should be done to generate added value and produce products that benefit society. The purpose of this research is to develop alternative productbased on natural fiber composites of Indonesia. Banana fiber has good potential to be developed into strong biocomposite materials, cheap, environmentally friendly and recyclable. Banana fiber composite materials developed will be applied as a prosthesis socket materials.

John Craig and Poonekar[1,2] recommends that the development of a prosthesis can refer to the local potential, the issue of the environment, go green, back to nature and reduction of hazardous waste. Sam L. Phillips et al. [3] stated that the requirements above knee prosthesis material must be lightweight, non-corrosive, resistant to water, resistant to shock loads and does not interfere with the user's health. Materials socket prosthesis which will be discussed in this study are composite materials, especially natural fiber composites begins with the gathering of data that support the use of composite materials in the design of the product. The results of their study of composite laminates with fiber orientation $\pm 45^{\circ}$ for fiber Perlon, nyglass, nylon, cotton, and spectralon. While fiberglass cloth and carbon fiber with fiber orientation $0 / 900$, and fiberglass matte with random fiber orientation. The matrix used was laminhartz 80-20 (Ottobock), epoxyacryl (ForeSee), and Lamination Resin 80-20 (IPOS). Results obtained are as follows: the first group nyglass, spectralon, nylon, and cotton with the strength (16-42) $\mathrm{MPa}$, the second group with the strength of fiberglass (60-109) $\mathrm{MPa}$, the third group with the greatest power is carbon fiber laminate (185-249) $\mathrm{MPa}$ [3].

J.A. Campbell [4] states that a variety of materials have been used in the development of a prosthesis, such as metals, polymers, composites, and natural materials such as wood and leather. Selection of materials considering the functional requirements, costs, manufacturing processes, availability of materials, the process of repair and maintenance. 


\section{Material and Method}

\section{Material}

The manufacturing process of the test sample by using a fiber volume fraction (vf): $10 \%, 20 \%$, $30 \%, 40 \%$ and $50 \%$. The data fibers and treatment are carried out as shown in Table 1 .

Table 1. BFRECM Test Samples

\begin{tabular}{|c|c|c|c|c|}
\hline Fiber & Dimension & Treatment & Fiber Orientation & Matrix \\
\hline $\begin{array}{c}\text { Banana } \\
\text { Fiber }\end{array}$ & $\begin{array}{l}\text { Thickness }(0.4 \pm 0.05) \mathrm{mm} \\
\text { Width }(4 \mathrm{~mm} \pm 0.5 \mathrm{~mm}) \\
\text { Length } 1000 \mathrm{~mm}\end{array}$ & $\begin{array}{l}\text { Soaked in } 90 \% \\
\text { alcohol for } 30 \mathrm{~min}\end{array}$ & $0^{0} / 90^{0}$ & Epoxy \\
\hline
\end{tabular}

\section{Method}

The process to produce of the composite sample test by using compressed and vacuum processes. The compress and vacuum process aims to make epoxy resins can be entered into the fibers well, refer ASTM Standard [5]. The purpose of this process is to enable the strong bond between the fibers and the epoxy matrix. The compress and vacuum process also aims to produce the composite sample test without voids. Voids can cause failure of the composite material. The tensile testing of a sample test conducted in accordance with ASTM D3039/D3039Mstandard by using the Universal Testing Machine Shimadzu AGS- $10 \mathrm{k}$ NG, room temperature $22^{\circ} \mathrm{C}$, relative humidity of $64 \%$. The cross-head speed for tensile testing was $2 \mathrm{~mm} / \mathrm{min}$. Six samples were tested for tensile testing. The average values were reported including standard deviations. The position of the samples and the process of tensile testing as shown in Fig. 1. Based on tensile testing will be obtained for tensile strength and modulus of elasticity of the BFRECM[6].

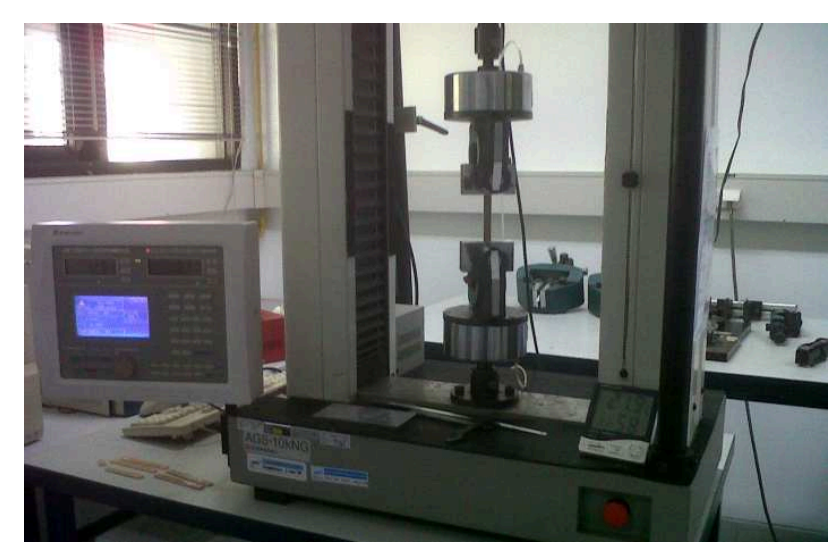

Fig. 1. Tensile Testing

\section{Result and Discussion}

Based on the test results (Fig. 2), it appears that the fiber volume fraction of $40 \%$, tensile strength BFRECM $(62.3 \pm 0.67) \mathrm{MPa}$, the modulus of elasticity $(8.72 \pm 1.12) \mathrm{GPa}$. When compared with materials commonly used as a prosthesis material as determined by the Sam L. Phillips et al [3], the banana fiber composite yield strength in the medium range of glass fibers, with a tensile strength (60-109) MPa and modulus of elasticity (5.0-17.3) GPa.

Based on the research results of Maleque et al [7], the tensile strength of banana fiber epoxy composite yield strength between (44-50) MPa with a modulus of elasticity of 1.9 GPa. The results obtained from this research is still in the range of research of Maleque et al. The differences in the results of the study are caused by the choice of banana fibers, treatment is carried out before the composite manufacturing processes and methods of composite manufacturing processes. Hariprasad 
et al [8] state that an alkali-treated banana-coir epoxy hybrid composite has greater tensile strength and impact strength than an untreated banana-coir epoxy hybrid composite. Differences with research of Maleque et al [7], and Hariprasad et al [8], in this study the banana fiber soaked in 90\% alcohol for 30 minutes. The results of the research are very good and can contribute in adding the information related to the tensile strength and modulus of elasticity of the BFRECM. The BFRECM characteristics such as tensile strength and modulus of elasticity of the product can meet the needs of a prosthesis socket refer to several studies that have been published previously.

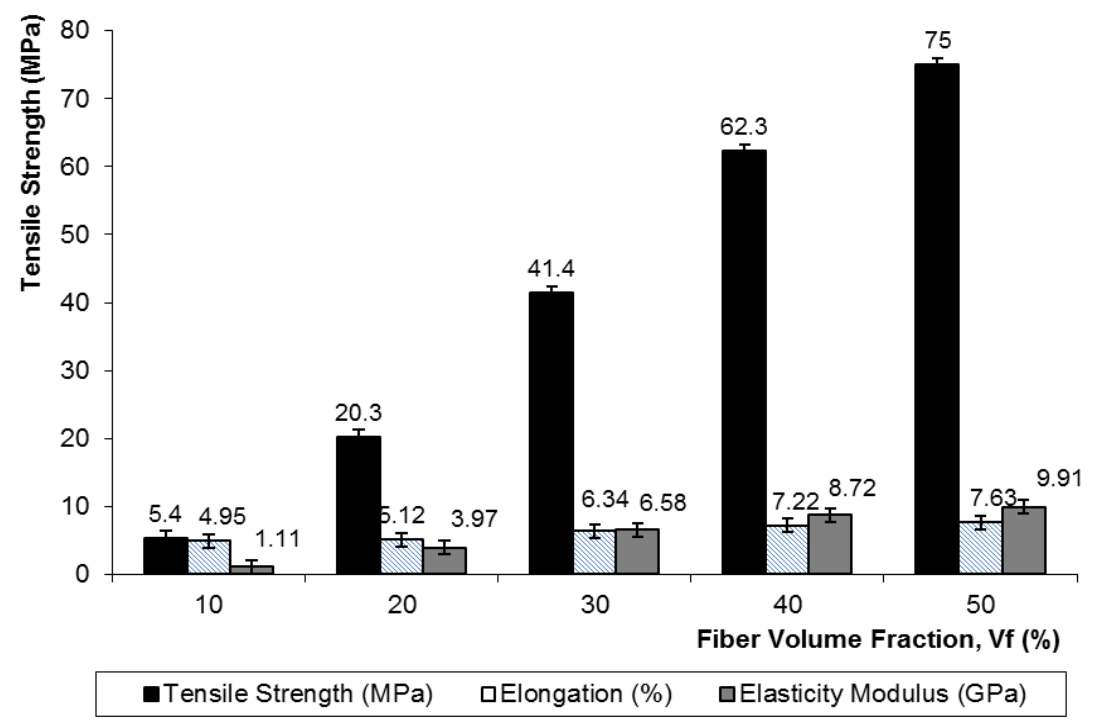

Fig. 2.Tensile Testing Result of BFRECM

When compared with the results of the study of Agustinus et al [9-12] and several other studies, it can be made a comparison of tensile strength and modulus of elasticity of composite fiber banana with ramie fiber reinforced epoxy composite, bamboo fiber reinforced epoxy composite and rattan fiber reinforced epoxy composite following Table 2.

Table 2.Comparison of Tensile Strength of Composite Materials[3,7,9-12]

\begin{tabular}{|c|c|c|c|}
\hline Strength Range & Fiber Types & UTS Range (MPa) & Young's Modulus (GPa) \\
\hline \multirow{4}{*}{ Low } & $\begin{array}{c}\text { Perlon, nylon, cotton, } \\
\text { nyglass, spectralon***) }\end{array}$ & $18-42$ & $1.8-5.1$ \\
\hline \multirow{5}{*}{ Middle } & Glass***) & $67-109$ & $5.0-17.3$ \\
\cline { 2 - 4 } & Rattan Epoxy*) & $65.25 \pm 0.81$ & $8.68 \pm 0.68$ \\
\cline { 2 - 4 } & Ramie Epoxy*) & $86 \pm 6.07$ & $9.56 \pm 0.68$ \\
\cline { 2 - 4 } & Bamboo Epoxy*) & $78.09 \pm 1.97$ & $8.96 \pm 0.33$ \\
\cline { 2 - 4 } & Ramie Polyester*) & $67 \pm 5.11$ & $7.45 \pm 0.57$ \\
\cline { 2 - 4 } & Fiberglass Polyester*) & $62 \pm 4.20$ & $6.89 \pm 0.47$ \\
\cline { 2 - 4 } & Banana Epoxy*) & $62.3 \pm 0.67$ & 1.9 \\
\cline { 2 - 4 } & Banana Epoxy**) & $44-50$ & $20.6-25.5$ \\
\hline High & Carbon***) & $236-249$ & 1.12 \\
\hline Remarks: *) Agustinus et al., **) Maleque et al., ***) Sam L. Phillips et al. \\
\hline
\end{tabular}




\section{Conclusion}

Based on test results, obtained tensile strength $(62.3 \pm 0.67) \mathrm{MPa}$, modulus of elasticity $(8.72 \pm$ 1.12) GPa. The BFRECM tensile strength is in the medium range. The mechanical characteristics of a material are very important to know well, so it can produce a product that has good strength in accordance with requirements. The mechanical characteristic can also be used to improve the manufacturing process, so that the resulting product could be improved with a low failure rate. The results of this test can be used as a reference in the next research of banana fiber reinforced epoxy composites materials, especially for prosthesis socket application.

\section{Acknowledgements}

The Authors wish to thanks DiktiKemdikbud and TarumanagaraUniversity for the financial support through Research University Grant Scheme 2014 vote number 192/K3/KM/2014.

\section{References}

[1] J. Craig,Prosthetic feet for low-income countries, J. of Pros. 17 (2005) 27-49.

[2] J.Biagiotti, D. Puglia, L. Torre, J.M. Kenny,A systematic investigation on the influence of the chemical treatment of natural fibers on the properties of their polymer matrix composites, Polymer Composites. 25 (2004) 470-479.

[3] S. L. Phillips, W.Craelius,Material properties of selected prosthetic laminates, J. Pros. 17 (2005) 2732.

[4] A.K. Kaw, Mechanics of Composite Materials,second ed., CRC Press, New York, 2006.

[5] ASTM,Annual Book of ASTM Standard,West Conshohocken, 2003.

[6] M. A. Maleque, F. Y. Belal, S.M. Sapuan,Mechanical properties study of pseudo-stem banana fiber reinforced epoxy composite, The Arabian J.for Sci, 32 (2007) 359-364.

[7] J.A. Campbell, Material Selection in an above Knee Prosthetic Leg,Engineering Materials, Department of Engineering, Australian National University, 2002.

[8] T. Hariprasad, G. Dharmalingam, P.P. Raj, Study of mechanical properties of banana-coir hybrid composite using experimental and fem techniques, J. of MES, 4 (2013) 518-531.

[9] A.P. Irawan, T.P. Soemardi, W. Kusumaningsih, A.H.S. Reksoprodjo, Ramie epoxy laminate composite for alternative prosthesis socket materials, J. Teknik Mesin, 11 (2009) 41-45.

[10] A.P.Irawan, T.P. Soemardi, W. Kusumaningsih, A.H.S. Reksoprodjo. Tensile and flexural strength of ramie fiber reinforced epoxy composites for socket prosthesis application. Int. J. of Mech and Mat. Eng., 6 (2011) 46-50.

[11] A.P.Irawan, I.W. Sukania, Mechanical characteristics rattan fiber reinforced epoxy composites (RECO) as above knee socket prosthesis materials,Proc. of IPST (2011) 64-70

[12] A.P. Irawan, I.W. Sukania,Tensile and impact strength of bamboo fiber reinforced epoxy composite as alternative materials for above knee prosthesis socket,Proc. of ICSTD (2012) M.109-M.115. 